\title{
Adrian P. Tudor, Tales of Vice and Virtue. The First Old French 'Vie des Pères'
}

\section{Maria Colombo Timelli}

\section{(2) OpenEdition}

10 Journals

\section{Édition électronique}

URL : https://journals.openedition.org/studifrancesi/25978

DOI : $10.4000 /$ studifrancesi.25978

ISSN : 2421-5856

Éditeur

Rosenberg \& Sellier

\section{Édition imprimée}

Date de publication : 1 avril 2007

Pagination : 151-152

ISSN : 0039-2944

\section{Référence électronique}

Maria Colombo Timelli, «Adrian P. Tudor, Tales of Vice and Virtue. The First Old French 'Vie des Pères' », Studi Francesi [En ligne], 151 (LI | I) | 2007, mis en ligne le 30 novembre 2015, consulté le 23 novembre 2021. URL : http://journals.openedition.org/studifrancesi/25978; DOI : https://doi.org/10.4000/ studifrancesi. 25978

Ce document a été généré automatiquement le 23 novembre 2021.

\section{(c)}

Studi Francesi è distribuita con Licenza Creative Commons Attribuzione - Non commerciale - Non opere derivate 4.0 Internazionale. 


\title{
Adrian P. Tudor, Tales of Vice and Virtue. The First Old French 'Vie des Pères'
}

\author{
Maria Colombo Timelli
}

\section{RÉFÉRENCE}

ADRIAN P. TUDOR, Tales of Vice and Virtue. The First Old French 'Vie des Pères'. Preface by

Michel zINK, Amsterdam - New York, NY, Rodopi («Faux Titre», 253), 2005, pp. 612.

1 Transmis par plus de cinquante manuscrits, le recueil que l'on désigne comme la Première Vie des Pères constitue un richissime réservoir de récits pieux destinés à l'édification du public. Cet ensemble, qui compte 20000 vers environ, fut composé vers 1215-1230, peu après le IV ${ }^{e}$ Concile du Latran (1215) dont il reflète l'attention pour la pénitence comme condition pour mériter le salut éternel: de fait, nombre des contes sont centrés non seulement sur la repentance à l'égard du ou des péchés commis, mais surtout sur les pratiques d'expiation que les protagonistes s'infligent afin de gagner le paradis. Sans fournir un véritable récit-cadre, le recueil repose néanmoins sur une structure tripartite, dans laquelle un prologue général introduit la matière en insistant sur son authenticité, et la conclusion exhorte à prendre exemple de Jésus Christ et dédie le corpus à la Vierge; de manière analogue, dans chaque unité narrative le récit véritable est entouré d'un prologue et d'un épilogue qui en soulignent le sens et l'interprétation. La Première Vie des Pères (il n'est peut-être pas inutile de rappeler qu'elle fut suivie, au xIII ${ }^{\mathrm{e}}$ siècle, de deux autres recueils, tous édités par Félix Lecoy pour la «SATF» en 1987, 1993, 1999) a retenu jusqu'ici l'attention de la critique principalement sur le plan de l'intertextualité, tant pour la recherche des sources que pour la circulation de certains motifs particulièrement répandus au Moyen Âge (et il est incontestable que plusieurs sujets reviennent tant dans la Vie que dans les exempla et dans certains fabliaux, voire dans des romans). Dans une perspective innovatrice, Peter 
A. Tudor concentre son gros travail de lecture essentiellement sur le sens que ces textes, qui se lisent toujours avec plaisir, pouvaient assumer aux yeux de l'auteur qui les a composés et regroupés et du public, formé soit d'auditeurs soit de lecteurs. Il souligne d'abord ce qui fait l'intérêt, non seulement littéraire, des récits: centrés tout spécialement sur la confession, comme on l'a dit, ils poursuivent un but d'édification; mais la narration demeure vive et immédiate, et la piété dont font preuve les protagonistes ne les éloigne jamais de la réalité de la vie quotidienne.

2 Peter A. Tudor a organisé sa propre lecture des quelque quarante épisodes en question autour des fondements de la foi chrétienne: les dix commandements, les sept péchés capitaux et les sept vertus. Une telle subdivision, qui nécessairement ne tient pas compte de l'ordre des récits dans les différents manuscrits (ordre par ailleurs très variable), permet surtout de mettre en relief les ressemblances et parallélismes qui caractérisent l'ensemble. Ceci dit, le rapport entre les épisodes retenus et le commandement, vice ou vertu, qu'ils sont censés illustrer n'est pas toujours limpide; d'autre part, quelques contes rentreraient aisément dans des 'chapitres' différents de ceux où ils sont situés: mais il s'agit de risques dont $\mathrm{M}$. Tudor est pleinement conscient et qui n'enlèvent rien de l'intérêt de l'ensemble.

3 Ainsi, la première partie du volume compte quatre chapitres, chacun d'entre eux consacré à deux ou plusieurs commandements: les deux premiers sont illustrés par Juitel, Sarrasine, Renieur, Païen, Crucifix, Image du Diable (on aura reconnu les intitulés proposés par G. Paris, «Romania», XIII, 1884); sous les troisième, quatrième et cinquième commandements sont rangés Miserere, Ave Maria, Demi-ami, Vision de Diables, Vision d'enfer; suivent Meurtrier, Ivresse, Prévôt d'Aquilée pour les sixième et septième commandements; et, pour les trois derniers, Goliard, Ermite accusé, Impératrice. On retrouve la même subdivision dans la seconde partie; quatre péchés capitaux - orgueil, avarice, luxure, envie - sont exemplifiés par Queue, Merlot, Sénéchal, Brûlure, Nièce, Inceste, Colombe, les trois autres - gourmandise, colère, paresse - par Crapaud, Haleine, Baril. Les quatre vertus cardinales - prudence, tempérance, fortitude, justice - sont ensuite illustrées par Feuille de chou, Noël, Malaquin, Copeaux, Fou, Sacristine, Abbesse grosse; les trois vertus théologales - foi, espérance, charité - par Fornication imitée, Jardinier, Thaïs, Image de pierre, Usurier, saint Paulin, Rachat. Relevons encore qu'un résumé détaillé de chaque conte est donné en ouverture des différents chapitres, ce qui permet au lecteur d'en rafraîchir la mémoire et de mieux situer les citations qui émaillent l'analyse.

Un appendice (pp. 581-584) donne la liste des éditions partielles dont ont joui certains épisodes de la Première, Deuxième, Troisième Vies; une riche bibliographie raisonnée occupe les pp. 585-612.

5 Si l'édition de Félix Lecoy a permis l'accès à un ensemble narratif imposant, encore inédit dans sa totalité il y a dix ans, l'étude de Peter A. Tudor doit être saluée comme la première tentative d'en offrir une lecture systématique et complète. Relevons, et ceci n'est qu'un souhait, que nous n'en sommes encore qu'à un tiers de la tâche. 